\title{
Involvement of Sox-4 in the cytochrome c-dependent AIF-independent apoptotic pathway in HeLa cells induced by $\Delta^{12}$-prostaglandin $\mathrm{J}_{2}$
}

\author{
Boe-Eun Kim ${ }^{1}$, Jeong-Hwa Lee ${ }^{1}$, \\ Ho-Shik Kim ${ }^{1}$, Oh-Joo Kwon ${ }^{1}$, \\ Seong-Whan Jeong ${ }^{1}$ and In-Kyung Kim ${ }^{1,2}$ \\ ${ }^{1}$ Department of Biochemistry \\ College of Medicine, The Catholic University of Korea \\ Seoul 137-701, Korea \\ ${ }^{2}$ Corresponding author: Tel, 82-2-590-1175; \\ Fax, 82-2-596-4435; E-mail, ikkim@ catholic.ac.kr
}

Accepted 21 September 2004

Abbreviations: $\triangle^{12}-P G J_{2}, \triangle^{12}$-prostaglandin $\mathrm{J}_{2} ;$ AIF, apoptosisinducing factor; Sox-4, SRY-HMG box protein-4; z-VAD-fmk, Benzyloxycarbonyl-Val-Ala-Asp(OMe) fluoromethyl ketone

\begin{abstract}
$\Delta^{12}$-Prostaglandin (PG) $J_{2}$ is known to elicit an anti-neoplastic effects via apoptosis induction. Previous study showed $\triangle^{12}-P G J_{2}$-induced apoptosis utilized caspase cascade through cytochrome c-dependent pathways in HeLa cells. In this study, the cellular mechanism of $\triangle^{12}-P G J_{2}-$ induced apoptosis in HeLa cells, specifically, the role of two mitochondrial factors; bcl-2 and apoptosis-inducing factor (AIF) was investigated. $\mathrm{Bcl}-2$ attenuated $\triangle^{12}-P G J_{2}$-induced caspase activation, loss of mitochondrial transmem. brane potential $\left(\Delta \psi_{m}\right)$, nuclear fragmentation, DNA laddering, and growth curve inhibition for approximately $24 \mathrm{~h}$, but not for longer time. AIF was not released from mitochondria, even if the $\Delta \psi_{\mathrm{m}}$ was dissipated. One of the earliest events observed in $\triangle^{12}-P G J_{2}$-induced apoptotic events was dissipation of $\Delta \psi_{m}$, the process known to be inhibited by bcl-2. Pre-treatment of z-VAD$\mathrm{fmk}$, the pan-caspase inhibitor, resulted in the attenuation of $\Delta \psi_{m}$ depolarization in $\Delta^{12}-\mathrm{PGJ}_{2^{-}}$ induced apoptosis. Up-regulation of Sox-4 protein by $\triangle^{12}-P G J_{2}$ was observed in $\mathrm{HeLa}$ and bcl-2 overexpressing $\mathrm{HeLa} B 4$ cell lines. Bcl-2 overexpression did not attenuate the expression of Sox-4 and its expression coincided with other apoptotic events. These results suggest that $\triangle^{12}-\mathrm{PGJ}_{2}$ induced Sox-4 expression may acti-
\end{abstract}

vate another upstream caspases excluding the caspase 9-caspase 3 cascade of mitochondrial pathway. These and previous findings together suggest that $\triangle^{12}-P J_{2}$-induced apoptosis in $\mathrm{HeLa}$ cells is caspase-dependent, AIF-independent events which may be affected by Sox-4 protein expression up-regulated by $\triangle^{12} \cdot P G J_{2}$.

Keywords: AIF; Apoptosis, Caspase; $\triangle^{12}-\mathrm{PGJ}_{2}$; Sox-4

\section{Introduction}

$\triangle^{12}$-Prostaglandin(PG) $J_{2}$ is a cyclopentenone prostaglandins(PGs) which were known to have antiproliferative effects on various tumour cell growth (Kim et al., 1993; Kim et al., 2002). $\triangle^{12}-\mathrm{PGJ}_{2}$ is an enzymatic dehydration product of $\mathrm{PDJ}_{2}$ (Fukushima et al., 1982; Fukushima et al., 1994) and $\Delta^{12}-P G J_{2}$ was able to induce apoptosis in HeLa cells via caspase activation (Kim et al., 2003). PGs are also reported to regulate expression of variable genes, including Sox-4 (Ahn et al., 2002), Ssf-1 (Ahn et al., 1999), c-myc and hsp70 (Ahn et al., 1998), and these genes seem to positively or negatively regulate the cell death in many tumour cells. $\triangle^{12}-P G J_{2}$-induced Sox-4 is one of the Sox (SRY-HMG box containing) proteins which are assumed to be involved in the regulation of developmental stages in several tissues. As a transcription factor containing serine-rich trans-activation domain, Sox-4 was selectively expressed in liver and thymus (van de Wetering et al., 1993). Sox-4 expression was induced during $\triangle^{12}-P_{G}$-induced apoptosis (Ahn et al., 1999; 2002) and demonstrated to induce apoptosis directly (Hur et al., 2004). Sox-4 is thought to be an important mediator of apoptosis, but its actual process is not clarified yet.

Mitochondria is emerging as the key regulator of apoptosis. Most of the mechanisms characterized appeared to indicate intimate involvement of signaling via mitochondria. Two different pathways have been exerted (Ly et al., 2003; Maria et al., 2003; Tomomi et al., 2003; Xavier et al., 2004); one is the caspase cascade, activation of cysteine-aspartic acid proteases through mitochondrial factor, cytochrome $c$, and this process is regulated by bcl-2 family, and the other is an apoptotsis inducing factor (AIF), which is known to trigger apoptotic mitochondrial events and respon- 
sible for caspase-independent nuclear fragmentation via unknown processes (Stuart et al., 2002; Sean et al., 2004). Process of AIF is not examined closely enough, but bcl-2 overexpression is known to inhibit translocation of AIF. Generally those two pathways were thought to work independently, and which signaling pathway should be utilized is up to various conditions, cell types and sorts of stimuli, etc. Some cases reported that both caspases and AIF were activated in same stimuli (David et al., 2001; Isabel et al., 2001; Sai et al., 2001; Tong et al., 2004; Xu et al., 2004). Some of the apoptotic stimuli pass through the caspase-dependent and AIF-independent pathway (Ella et al., 1998; Neeru et al., 2004) or caspase-independent and AIF-dependent (Sean et al., 2002; Bains et al., 2003; Kim et al., 2003), and others reported that ROS production is implicated in CD47mediated cell death without cytochrome c nor AIF release (Gael et al., 2003). Moreover, Damien et al. reported that mitochondrial release of AIF might occur downstream of cytochrome c release (Damien et al., 2002; Damien et al., 2003). In this study, the mechanisms of $\triangle^{12}-\mathrm{PGJ}_{2}$-induced apoptosis pathway in HeLa cells was investigated specifically focusing on two mitochondrial factors, bcl-2 for the caspase-dependent pathway and AIF for the caspase-independent pathway. And also we observed the effect of Sox4 in $\triangle^{12}-\mathrm{PGJ}_{2}$-induced apoptosis, for $\triangle^{12}-\mathrm{PGJ}_{2}$ induced Sox-4 expression was reported to induce the apoptosis directly.

\section{Materials and Methods}

\section{Reagents}

$\triangle^{12}-P G J_{2}$ was obtained from BioMol (Plymouth Meeting, $P A)$ and pan-caspase inhibitor Benzyloxycarbonyl-Val-Ala-Asp (OMe) fluoromethyl ketone (z-VAD$\mathrm{fmk}$ ) was from Enzyme Systems Products (Livermore, CA). Protease inhibitor cocktail was from Roche Molecular Biochemicals (Mannheim, Germany). Agonistic anti-Fas antibody (CH11) and antagonistic anti-Fas antibody (ZB4) were from Upstated Biotechnology (Lexington, KY). 3-(4,5-Dimethylthiazol-2-yl) 2,5-diphenyltetrazolium bromide (MTT) and Hoechst 33342 were from Sigma (St. Louis, MO). Anti-caspase 3, -8, -9 antibodies were from Cell Signaling Technology (Beverly, MA), anti-cytochrome c, AIF, heat-shock protein(hsp)60 antibodies were from Santa Cruz (Santa Cruz, CA) and anti-Bcl-2 was from Delta Biolabs (Campbell, CA). Anti-Sox-4 antibody was manufactured in Koma Biotech (Seoul, Korea) using synthetic Sox-4 protein. Horseradish peroxidase(HRP)conjugated secondary antibody against rabbit and mouse IgG and anti- $\beta$-actin were from Sigma. FITClabeled and Texas Red-labeled secondary antibodies were all from Santa Cruz. Unless specified otherwise, all reagents were purchased from Sigma.

\section{Cell culture and viability assay}

Human cervical carcinoma HeLa cells were obtained from American Type Culture Collection (ATCC, Rockville, MD) and maintained in RPMI 1640 media supplemented with $10 \%$ heat-inactivated $\left(56^{\circ} \mathrm{C}\right.$ for 30 min) fetal bovine serum (Hycloned Laboratories Inc., Logan UT) and $100 \mathrm{U} / \mathrm{ml}$ of penicillin/streptomycin (Gibco BRL, Grand Island, NY) at $37^{\circ} \mathrm{C}$ in a humidified atmosphere of $5 \% \quad \mathrm{CO}_{2}$. HeLa cells stably overexpressing bcl-2 protein, HeLa B4, were gift from Prof. Lee and maintained in complete medium containing $0.5 \mu \mathrm{g} / \mathrm{ml}$ G418 (Gibco, Grand Island, NY).

To observe the effect of $\triangle^{12}-P J_{2}$ on the growth of HeLa and HeLa B4 cells, cell viability was determined by MTT assay. In brief, cells were plated in 96-well plates and then treated with indicated concentrations of $\triangle^{12}-P G J_{2}$. After incubation of indicated time, MTT reagent was added to final concentration of $500 \mu \mathrm{g} / \mathrm{ml}$. Three hours later, MTT crystals were collected and dissolved with isopropanol containing $0.04 \mathrm{~N}$ of $\mathrm{HCl}$ and the absorbance was measured at $570 \mathrm{~nm}$.

\section{Evaluation of apoptosis}

Induction of apoptosis was determined by fragmentation of genomic DNA. Cells were treated with 30 $\mu \mathrm{M}$ of $\triangle^{12}-\mathrm{PGJ}_{2}$ for indicated times, and then genomic DNA was extracted using DNA extraction buffer [5 $\mathrm{mM}$ Tris- $\mathrm{Cl} \mathrm{pH} 8.0,20 \mathrm{mM}$ EDTA $\mathrm{pH} 8.0,1 \%$ sodium dodecyl sulfate (SDS), $50 \mu \mathrm{g} / \mathrm{ml}$ proteinase $\mathrm{K}]$ and extraction with phenol-ethanol was followed. DNA pellets were dissolved in TE buffer $(10 \mathrm{mM}$ Tris-Cl $\mathrm{pH} 8.01 \mathrm{mM}$ EDTA pH 8.0) containing $20 \mu \mathrm{g} / \mathrm{ml}$ of RNase $A$ and incubated at $37^{\circ} \mathrm{C}$ for 1 h. $5 \mu \mathrm{g}$ of DNA was separated on $1.8 \%$ agarose gels with $1 \mathrm{X}$ TAE (20 mM Tris-acetate, $1 \mathrm{mM}$ EDTA). DNA in the gel was stained with ethidium bromide and visualized under UV light and photographed.

\section{Western blot analysis}

Cells were harvested and lysed with RIPA buffer[1\% Triton X-100, $20 \mathrm{mM}$ Tris-Cl, pH 7.5, $150 \mathrm{mM} \mathrm{NaCl}$, $0.5 \%$ deoxycholate, $0.1 \%$ SDS, $1 \mathrm{mM}$ EDTA] containing protease inhibitor cocktail. $30 \mu \mathrm{g}$ of each protein was separated in $12-15 \%$ SDS-polyacrylamide gel (PAGE), and transferred to a nitrocellulose membrane in transfer buffer [ $25 \mathrm{mM}$ Tris base, $193 \mathrm{mM}$ glycine, $20 \%$ methanol]. The membrane was blocked in $5 \%$ nonfat dried milk in phosphate-buffered saline (PBS) and then incubated with primary antibody in blocking solution at $4^{\circ} \mathrm{C}$, followed by extensive washing in PBS 
containing $0.1 \%$ Tween-20. The blot was then incubated with peroxidase-conjugated secondary antibody in blocking solution at room temperature, followed by washing in PBS containing $0.1 \%$ Tween-20. Antigen was detected using the enhanced chemiluminescence western blotting detection system(Amersham- Pharmarcia, Buckinhamshire, UK).

\section{Immunofluorescence microscopy}

Cells were grown on coverslips and incubated with $\triangle^{12}-P G J_{2}$ and $z-V A D-f m k$ for indicated times. Cells were fixed with $100 \%$ ice-cold methanol and then blocked with blocking buffer [10\% fetal bovine serum, $1 \%$ Albumin, bovine serum (BSA), $0.02 \%$ sodium azide, $1 \times P B S$ ] for $1 \mathrm{~h}$ at room temperature. Anti-AIF, anit-cytochrome $\mathrm{c}$ and anti-hsp 60 antibodies were diluted and applied to coverslips and incubated overnight at $4^{\circ} \mathrm{C}$. Coverslips were washed with $1 \times$ PBS, then FITC-labeled and Texas red-labeled second antibodies were applied and incubated for $1 \mathrm{~h}$ at room temperature keeping in the dark. After washing with $1 \times$ PBS, Hoechst 33342 was incubated in final 10 $\mu \mathrm{M}$ for $5 \mathrm{~min}$, mounted on slides and observed under a Carl Zeiss LSM510 confocal microscope.

\section{Flow cytometry analysis}

To evaluate $\triangle \psi m$, cells were treated with $30 \mu \mathrm{M}$ of $\triangle^{12}-P G J_{2}$ and $z-V A D-f m k$ for indicated times, then 10 $\mu \mathrm{g} / \mathrm{ml}$ of $5,5^{\prime}, 6,6^{\prime}$-tetrachloro-1,1',3,3'-tetraethylbenzimidazolecarbo-cyanine (JC-1; Molecular Probes, Eugene, OR) was treated for $10 \mathrm{~min}$ at room temperature. Cells were finally washed with $1 \times P B S$, resuspended in $200 \mu$ of $1 \times$ PBS and analyzed using FACScan flow cytometer (Becton Dickinson).

\section{Results}

\section{Effect of bcl-2 overexpression on} $\triangle^{12} \cdot P G J_{2}$-induced apoptosis

Ability of HeLa B4 cells to express bcl-2 stably was confirmed by western blot method. In Figure 1A, HeLa B4 cells clearly showed bcl-2 protein overexpressed in comparison with HeLa cells. Bcl-2 known to inhibit apoptosis was induced by various stimuli and its effect on $\triangle^{12}-P G J_{2}$-induced apoptosis was determined measuring growth inhibition curve (Figure 1B). The cells were treated with $\triangle^{12}-P G J_{2}$ for indicated time period and MTT assay was performed. Overex-
A

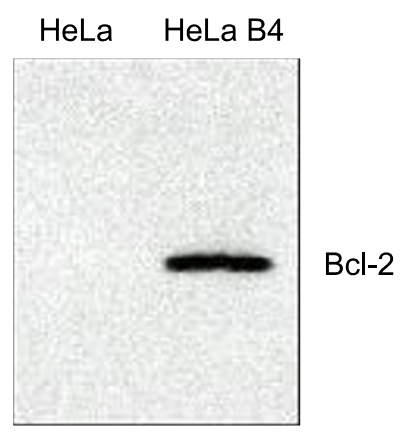

C

(h) $\mathrm{M} \quad \mathrm{C} \quad 6 \quad 12 \quad 2436 \quad 48 \quad 6072$



B

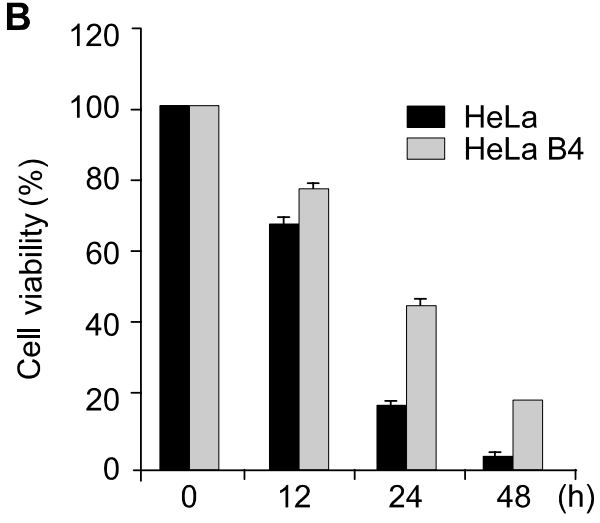

D

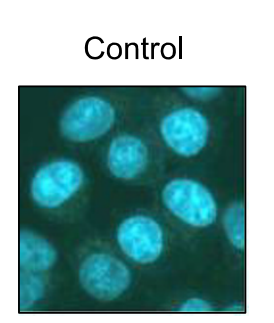

$+\Delta^{12}-\mathrm{PG} \mathrm{J}_{2}$

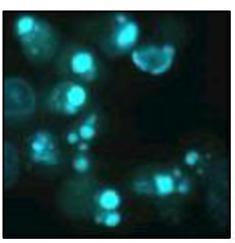

$\Delta^{12}-\mathrm{PG} J_{2}$ +Z-VAD-fmk

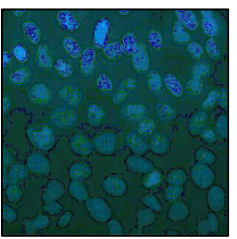

HeLa B4 $+\Delta^{12}-\mathrm{PGJ} 2$

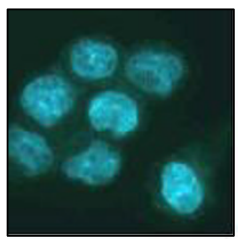

Figure 1. Effect of $\mathrm{BCl}-2$ overexpression on $\triangle^{1 / 2}$-PG $J_{2}$-induced apoptosis. (A) $\mathrm{BCl}-2$ overexpressing ability of HeLa $B 4$ cells was confirmed with Western blot compared to HeLa cells. (B) HeLa and HeLa B4 cells were treated with $30 \mu \mathrm{M}$ of $\triangle^{12} \cdot \mathrm{PGJ}_{2}$ as indicated time, and its growth curve was determined by MTT assay. Results were the mean \pm SD of three independent experiments. $P<0.01$, compared to control. (C) HeLa B4 cells were treated as above, and DNA laddering(C) was visualized in 1.5\% agarose gel. (D) HeLa and HeLa B4 cells were treated with or without $100 \mu \mathrm{M}$ of $z$-VAD-fmk for $1 \mathrm{~h}$ and then treated with $30 \mu \mathrm{M}$ of $\Delta^{12}-P G J_{2}$ for $24 \mathrm{~h}$, stained with Hoecst 33285 and observed under fluorescence microscopy in magnification of $\times 400$. 
pression of $\mathrm{Bcl}-2$ resulted in an inhibition of $\triangle^{12}$. $P \mathrm{PJ}_{2}$-induced cell death till $24 \mathrm{~h}$. DNA laddering
(Figure 1C) and nuclear fragmentation (Figure 1D) were not observed by $\mathrm{bcl}-2$ in this experiments. $\mathrm{Bcl}-2$
A

\section{Control}

a

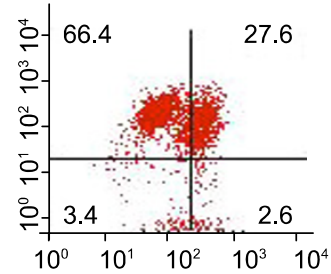

b

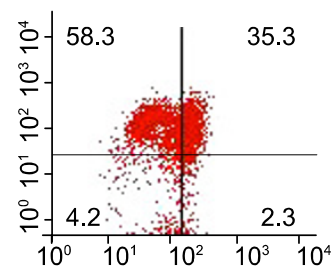

c

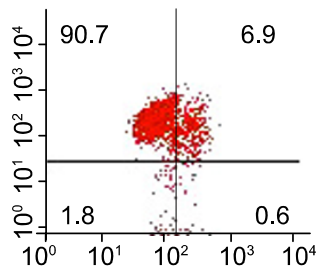

HeLa B4
$\Delta_{12} P G J_{2} 12 \mathrm{~h}$


$\Delta{ }_{12} P J_{2} 24 h$
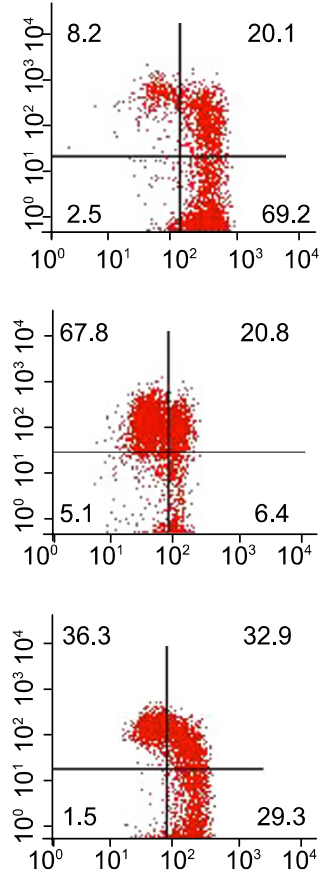
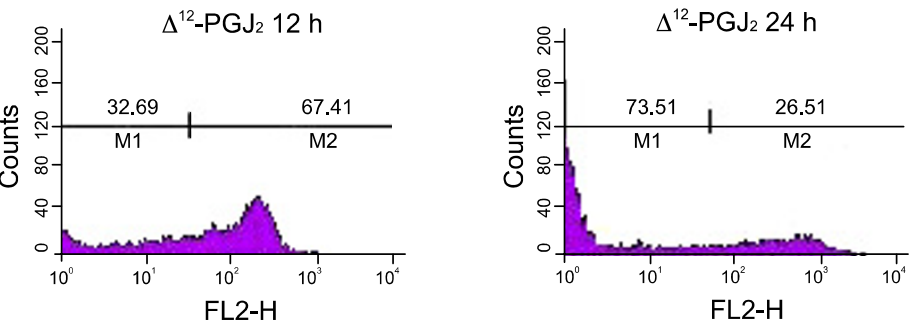

b
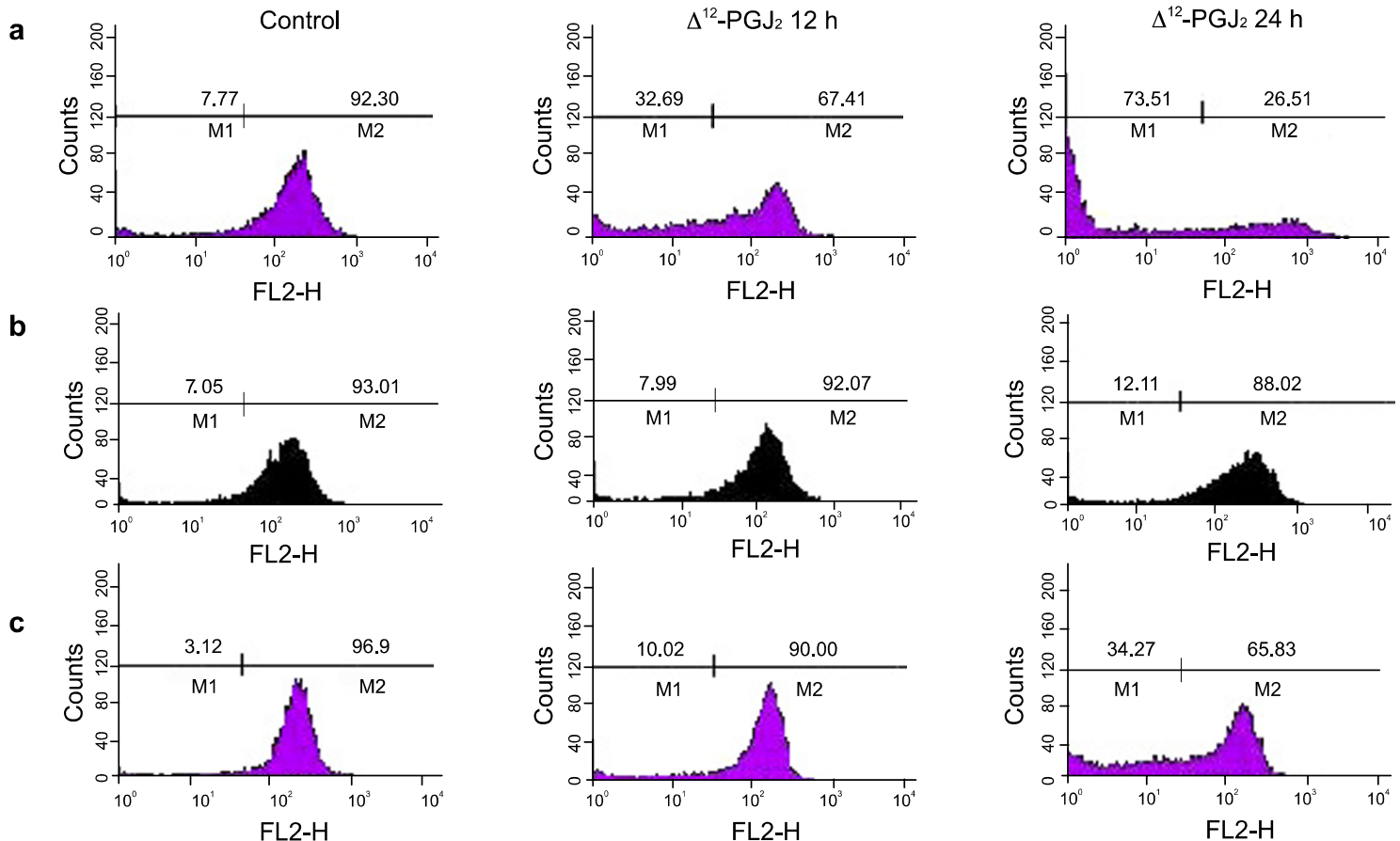

Figure 2. Effect of z-VAD-fmk and $B c l-2$ overexpression on $\Delta^{12}$ - PGJ -induced loss of $\Delta \psi_{m}$. HeLa $(a, b)$ and HeLa $B 4$ (c) cells were pretreated with or without $100 \mu \mathrm{M}$ of z-VAD-fmk(b) and then treated with $30 \mu \mathrm{M}$ of $\Delta^{12}-\mathrm{PGJ}_{2}(\mathrm{a}, \mathrm{c})$ for $24 \mathrm{~h}$, and $\Delta \psi_{\mathrm{m}}$ was estimated by flow cytometry using JC-1. (A) and (B) were performed twice, respectively. 
attenuation of the apoptosis induced by $\triangle^{12}-P G J 2$, was in effect for $24 \mathrm{~h}$ period. After $24 \mathrm{~h}$, inhibition of bcl-2 was abolished and growth rate dropped rapidly. In case of cisplatin induced apoptosis, inhibition by bcl-2 was effective for $48 \mathrm{~h}$, more than $50 \%$ of cells were kept alive (data not shown). This result shows that $\triangle^{12}-P G J_{2}$-induced apoptosis is mainly dependent to mitochondrial pathway, but there might be another pathway which does not associate with bcl-2 path.

\section{Depolarization of mitochondrial potential $\Delta \psi_{m}$} In order to determine mitochondrial integrity, the changes of $\Delta \psi_{\mathrm{m}}$ depolarization were measured. Cells were stained with the fluorescent dye $\mathrm{JC}-1$, and the flow cytometric assays were done (Figure 2). JC-1 exhibits potential-dependent accumulation in mitochondria. When mitochondrial depolarization proceeds in early stages of apoptosis, fluorescence of JC-1 turns from red to green. Figure $2 \mathrm{~A}$ shows the results of the induced mitochondrial depolarization at $12 \mathrm{~h}$ in HeLa cells treated with $30 \mu \mathrm{M}$ of $\Delta^{12}-\mathrm{PGJ}_{2}$, and this process was completed at $24 \mathrm{~h}$. In HeLa B4 cells, $\triangle^{12}-P G J_{2}$-induced depolarization was attenuated for $12 \mathrm{~h}$, but bcl-2 effect of maintaining $\Delta \psi_{\mathrm{m}}$ was abolished in $24 \mathrm{~h}$. FL2 (red) fluorescence shows the aggregated forms of $\mathrm{JC}-1$ which reflects $\Delta \psi_{\mathrm{m}}$, and is shown on Figure 2B. Histograms show more appa- rentl reduction of red fluorescences. Pretreatment of the cells with z-VAD-fmk also inhibited depolarization of $\Delta \psi_{\mathrm{m}}$ for $24 \mathrm{~h}$. These results imply that $\triangle^{12}-P \mathrm{GJ}_{2}$-induced $\Delta \psi_{\mathrm{m}}$ depolarization is downstream of caspase cascades, and suggests the existence of upstream caspases in mitochondria in $\triangle^{12}-P J_{2}$-induced apoptosis.

\section{Effect of bcl-2 overexpression in caspase-independent pathway; AIF}

AIF is known as another pathway that lead cells to apoptosis independently with caspase cascade. To test whether AIF pathway is involved in $\triangle^{12}-P_{G} J_{2}$ induced apoptosis, HeLa and HeLa B4 cells were treated with $30 \mu \mathrm{M}$ of $\triangle^{12}-\mathrm{PGJ}_{2}$, and subcellular localization of AIF was tested by immunofluorescence microscopy (Figure 3). As shown in Figure 3, AIF was neither released to cytosolic fraction nor redistributed to nuclei. Also in HeLa B4 cells, overexpression of bcl-2 had no effects on AIF translocation. AIF was thought not to involve in $\triangle^{12}-P J_{2}$-induced apoptosis, and we could not find any signs of release of AIF from mitochondria to cytosol.

\section{Effect of bcl-2 overexpression in caspase-dependent pathway}

Cytochrome $c$ released from the effected mitochondria
AIF
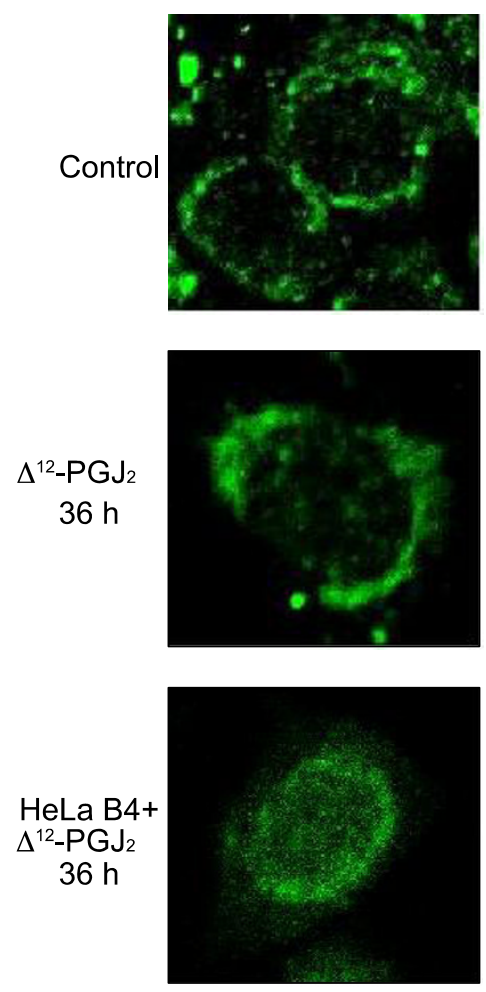

hsp60
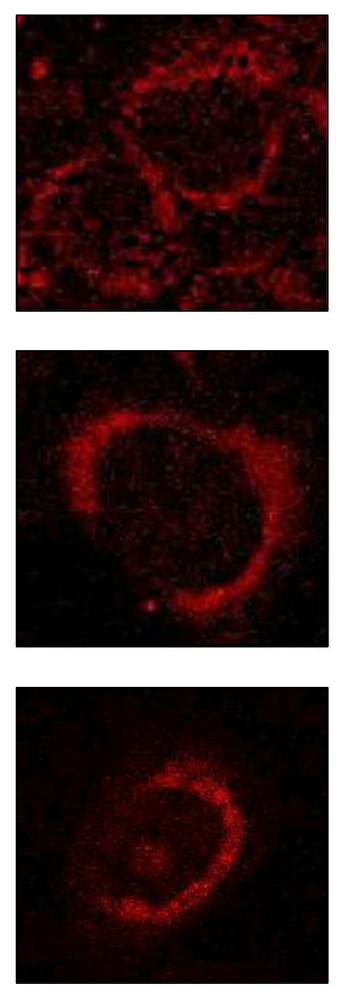

imerged
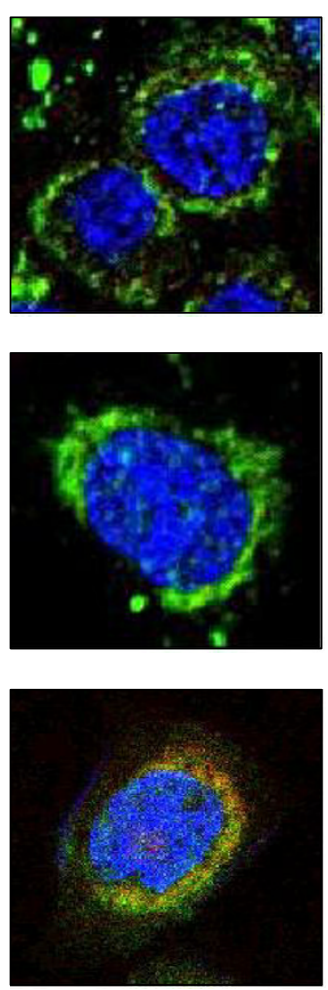

Figure 3. Translocation of AIF in $\Delta^{12}$. $P G J_{2}$-induced apoptosis. HeLa and HeLa B4 cells were treated with 30 $\mu \mathrm{M}$ of $\triangle^{12}-\mathrm{PG} J_{2}$, and immunostaining of AlF (FITC, green), hsp 60 (Texas Red, Red) together with nuclear Hoechst staining were shown under confocal microscopy in magnification of $\times 1,000$. Hsp 60 was shown as the marker of mitochondria. Three independent experiments were done which showed similar results. 
Cytochrome c
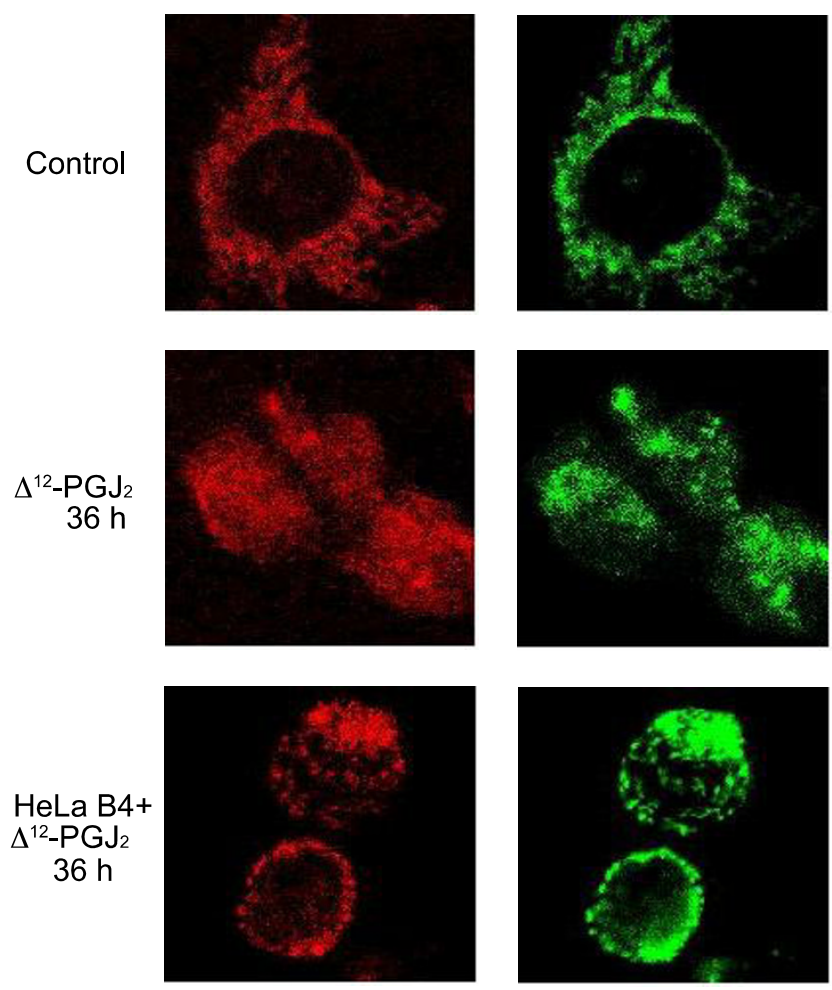

$\begin{array}{lllllllll}\text { (h) } & \text { c } & 6 & 9 & 12 & 18 & 24 & 36 & 48\end{array}$
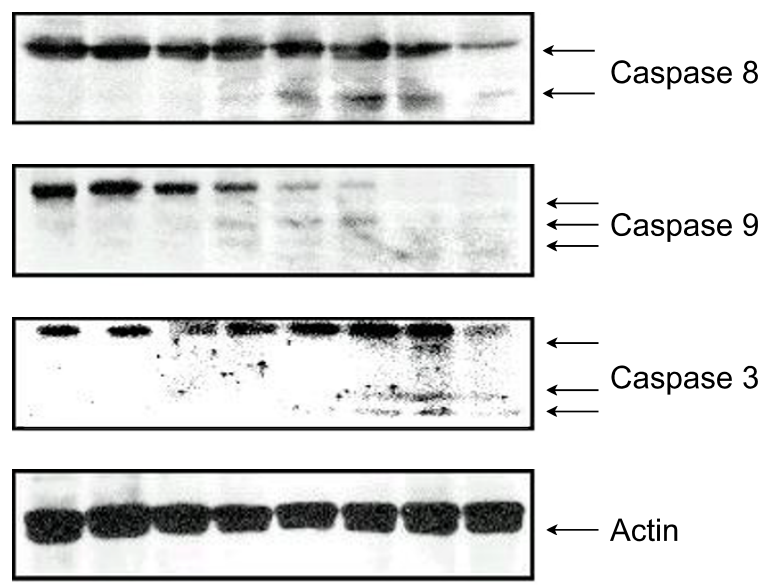

Figure 5. Effect of $b c l-2$ overexpression in $\triangle^{12}-P G J_{2}$-induced caspase activation. HeLa B4 cells were treated with $30 \mu \mathrm{M}$ of $\Delta^{12}-P G J_{2}$ for indicated time, and $30 \mu \mathrm{g}$ of cell lysates were separated by $12 \%$ SDS-PAGE, analyzed by western blotting for caspase 8 , caspase 9 and caspase 3 processing. Actin was shown as control.

was examined by immunofluorescence microscopy in $\triangle^{12}-P G J_{2}$-induced apoptosis. As shown in Figure 4, cytochrome $\mathrm{C}$ was released to cytosolic fraction in HeLa cells but in HeLa B4 cells overexpressing bcl-2, cytochrome $\mathrm{c}$ release was blocked in the same time imerged
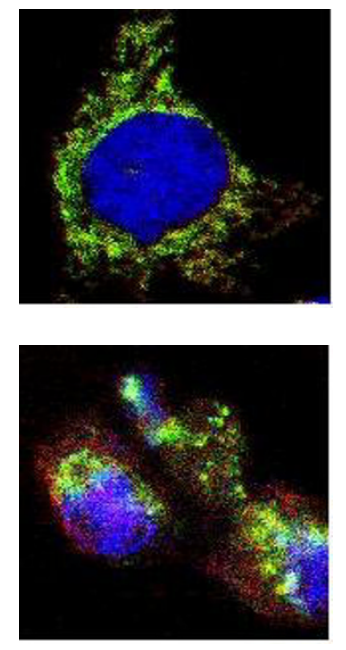

Figure 4. Release of cytochrome $c$ in $\triangle^{12}-P G J_{2}$-induced apoptosis. HeLa and HeLa B4 cells were treated with

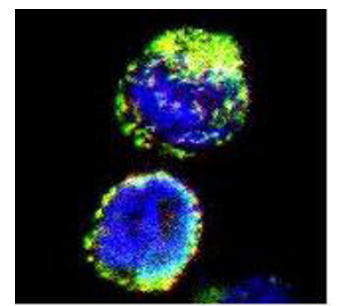
$30 \mu \mathrm{M}$ of $\triangle^{12}-P G J_{2}$, and immunostaining of cytochrome $c$ (Texas Red, Red), hsp 60 (FITC, green) together with nuclear Hoechst staining were shown under confocal microscopy in magnification of $\times 1,000$. Hsp 60 was shown as the marker of mitochondria. Three independent experiments were done which showed similar results.

period. This result affirms that $\mathrm{Bcl}-2$ overexpression inhibited cytochrome $c$ release in $\triangle^{12}-P_{G} J_{2}$-induced apoptosis.

In addition, in the HeLa B4 cells treated with 30 $\mu \mathrm{M}$ of $\triangle^{12}-\mathrm{PGJ}_{2}$ caspase activity was not observed till 12-18 $\mathrm{h}$ (Figure 5), suggesting that bcl-2 blocked cytochrome C mediated caspase activation. In previous study, caspases were found to be activated in 9-12 h in HeLa cells (Kim et al., 2003). In contrary, cisplatin induced caspase activation was almost completely blocked for $48 \mathrm{~h}$ (data not shown). These results demonstrate that bcl-2 was not able to block $\triangle^{12}-P G J_{2}$-induced apoptosis completely. Since caspase 8 was known to be activated slightly after caspase 9 and caspase 3 activation, we investigated whether caspase 8-activating Fas pathway was switched on. Caspase 8 can be activated in two pathways; one is Fas receptor-ligand interaction and the other is caspase 3-activated pathway. As shown in Figure 6, ZB4, the antagonistic Fas-antibody, blocked caspase 8 activation by agonistic Fas antibody $\mathrm{CH} 11$, but not that of $\triangle^{12}-P J_{2}$. These results represented that caspase 8 activation in $\triangle^{12}-P G J_{2}$-induced apoptosis was through caspase 3 -capsase 8 acticvation loop, and Fas receptor-ligand interaction was not involved.

We observed that $\triangle^{12}-\mathrm{PGJ}_{2}$-induced apoptosis in HeLa cells certainly activated caspase cascade in 

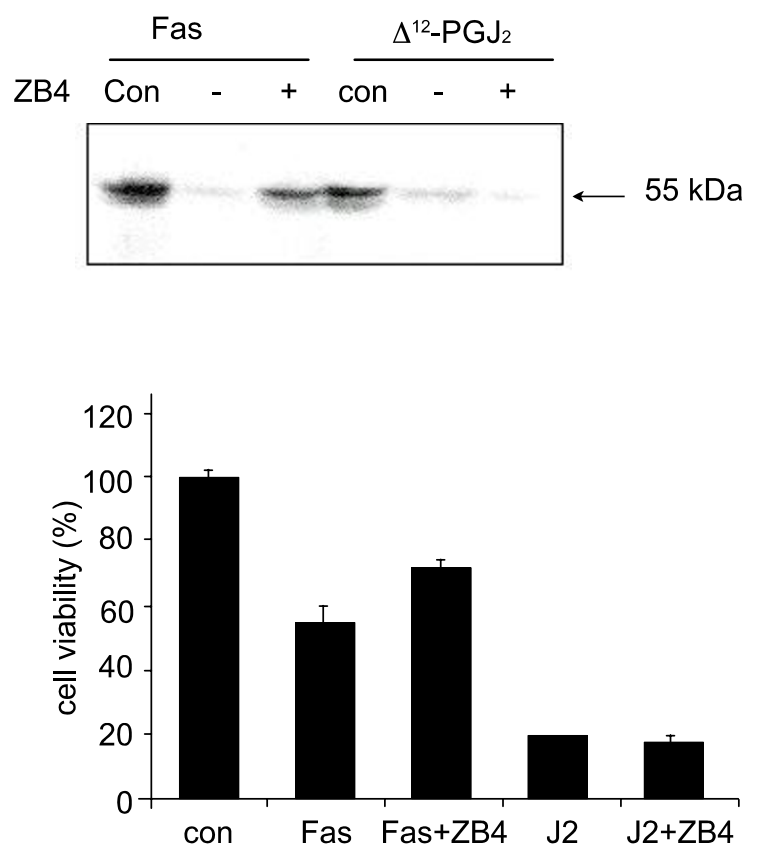

Figure 6. Involvement of Fas receptor in $\triangle^{12}-P G J_{2}$-induced caspase ○ activation. HeLa b4 cells were pretreated witn or witnout $\mathrm{bUU} \mathrm{ng} / \mathrm{mI}$ of ZB4, the antagonistic Fas-antibody, and then treated with $1 \mu \mathrm{g} / \mathrm{ml}$ of agonistic Fas-antibody $\mathrm{CH} 11$ and $30 \mu \mathrm{M}$ of $\triangle^{12}-\mathrm{PGJ}_{2}$. Western blotting was done with caspase 8 antibody, and cell viability was examined by MTT assay. Histogram represents the mean \pm SD of three independent experiments. $P<0.01$, compared to control. Fas indicates for agonistic Fas-antibody $\mathrm{CH} 11, \triangle^{12}-\mathrm{PGJ}_{2}$ for $\triangle^{12}-\mathrm{PGJ}_{2}$ and ZB4 for antagonistic Fas-antibody ZB4. cluding cytochrome $c$ and caspase 9-caspase-3 amplication loop, and both events were inhibited by bcl-2 overexpression.

\section{Expression of Sox-4}

$\triangle^{12}-P G J_{2}$ was shown to up- and down-regulate many apoptosis-related factors. Sox-4 is one of these molecules, and was found to act directly as regulator of apoptosis. Expression of Sox-4 was analyzed by either transfection of Flag-tagged Sox-4 or Western blot in HeLa. As shown in Figure 7C, both Sox-4 antibody and Flag-tag antibody revealed overexpressed signal at about $70 \mathrm{kDa}$. Estimated molecular weight of Sox-4 protein is $47.5 \mathrm{kDa}$, but those Sox-4 protein expressed in mammalian cells consistently appeared as $70 \mathrm{kDa}$ molecule. Such discrepancy in molecular size of Sox-4 may be due to post-translational modification of Sox-4. As shown in Figure 7A and B, Sox-4 was expressed in HeLa and HeLa B4 cells respectively induced by $\triangle^{12}-P G J_{2}$, and its expression was not attenuated in HeLa B4 cells. Sox-4 was reported to evoke apoptosis directly, and its expression pattern was coincident with other apoptotic events.

\section{Discussion}

Mitochondria have been noticed as heart of various forms of cell death, specially after findings of mitochondrial factors which involved in apoptosis regula-
A

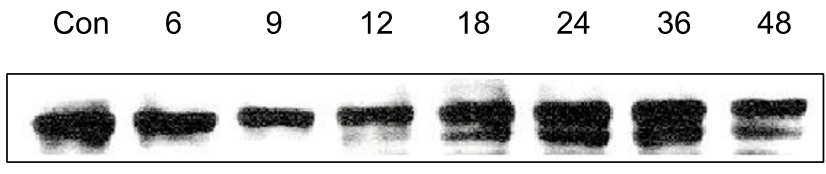
B

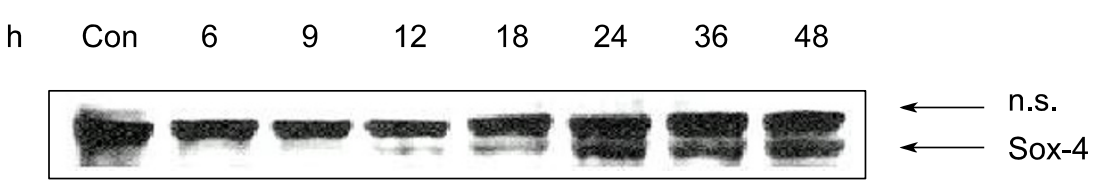
C

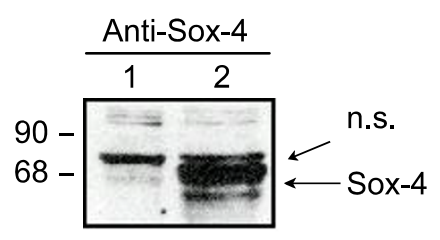

Figure 7. Expression of Sox-4 in $\triangle^{12}-P G J_{2}$-induced apoptosis. HeLa (A) and HeLa B4 (B) cells were treated with $30 \mu \mathrm{M}$ of $\triangle^{12}-P G J_{2}$ for indicated time, and $30 \mu \mathrm{g}$ of whole lysates were analyzed by western blot. Transfected Sox-4 in HeLa cells were shown on (C), which shows Sox-4 antibody and Flag antibody revealed as same where arrows indicate. Lane 1 and 3 were control vector transfected, 2 and 4 were Flag-tagged Sox-4 transfected. n.s. represents non-specific signals. 
tion. Bcl-2 family has been the standout molecule focused as anti-apoptotic regulators which are related to caspase cascade (Atan et al., 1999; Yoshihide et al., 2003). In addition numerous other proteins, DIABLO/SMAC (Stacy et al., 2002), AIF (Hans et al., 1999; Santos et al., 1999; Eric et al., 2000; Nele et al., 2004), endonuclease G (Li et al., 2001; Parrish et al., 2001; van Loo et al., 2001), were reported as apoptosis regulators which might act in caspasedependent or -independent manner. In murine glioma GL261 cells, CDK inhibitor, flavopiridol, accompanied the release of cytochrome $c$ together with translocation of AIF (Newcomb et al., 2003). And in cells from patients of $B$ cell chronic lymphocytic leukemia and human leukemic cell lines, apoptosis were induced by cladribine activated caspase cascade and translocated AIF to nuclei at the same time (Isabel et al., 2001; Perez-Galan et al., 2002). These reports lead us to examine the mitochondrial pathways of $\triangle^{12}-P G J_{2}$-induced apoptosis in $\mathrm{HeLa}$ cells.

In previous study, $\triangle^{12}-\mathrm{PGJ}_{2}$-induced apoptosis in HeLa cells (Kim et al., 2003) was accompanied with the release of cytochrome $c$ and activation of caspase cascade suggesting that $\triangle^{12}-P G J_{2}$-induced apoptosis in HeLa cells involves an activated cytochrome c-dependent pathway. To study the mechanism of $\triangle^{12}-P_{2} J_{2}$-induced apoptosis in Hela Cells, we examined caspase-independent pathway together with bcl-2 effects on caspase cascade. $\triangle^{12}-P J_{2}$ can exert its ability in many ways; through activation of caspase-1 (Ahn et al., 2002) or induce apoptosis regulators, like Sox-4, which directly plays a role in apoptosis (Hur et al., 2004). In the case of 15-deoxy$\triangle-12,14-P J_{2}\left(15 d-P G J_{2}\right)$, the hydrolysis product of $\Delta$ ${ }^{12}-\mathrm{PGJ}_{2}, \mathrm{CHOP}$ gene was transcriptionally activated to induce apoptosis (Shoichi et al., 2003). In $\Delta^{12}$. $\mathrm{PGJ}_{2}$-induced apoptosis in HeLa cells, bcl-2 overexpression results were in agreement with other previous reports of $\mathrm{Bcl}-2$ overexpression blockage of caspase activation and attenuated apoptosis. And AIF, another new regulator of caspase-independent pathway was not activated. Mechanism of $\Delta^{12}$ $P G J_{2}$-induced apoptosis was clearly caspase-dependent, AIF-independent pathway.

z-VAD-fmk study showed unexpected results. As a general caspase inhibitor, z-VAD-fmk usually inhibits caspase cascade in its downstream events. But as shown in Figure 2, z-VAD-fmk inhibited depolarization of $\Delta \psi_{\mathrm{m}}$, the earliest events in $\triangle^{12}-\mathrm{PGJ}_{2}$-induced apoptosis. In this case $\Delta \psi_{m}$ depolarization was apparently upstream of caspase 9-caspase 3 cascade. We reasoned that another caspase, excluding caspase 9, might exist upstream of mitochondria, activated by $\triangle^{12}-\mathrm{PGJ}_{2}$ or protein induced. In fact, caspase $8,-2$ or -1 were reported to be the upstream of $\Delta \psi_{m}$ dissipation. In an example, preotease activity of caspase 2 seems to be required as upstream of $\Delta \psi_{\mathrm{m}}$ dissipation (Patrice et al., 2002; Yin et al., 2002).

Prostaglandins and many other inflammatory stimuli induce the expression of genes. $\triangle^{12}-P G J_{2}$ seems to accumulate in ER (Senye et al., 1998), and PGinduced stress-protein gene expression requires de novo protein synthesis (Koizumi et al., 1993; Odani et al., 1996). This suggests that $\triangle^{12}-\mathrm{PGJ}_{2}$-induced apoptosis also requires the newly synthesized proteins. $\triangle^{12}-P G J_{2}$ especially induces Sox-4 protein and this phenomenon is restricted only to $\triangle^{12}-P G J_{2}$, but not to cisplatin (data not shown). Sox-4 was shown to be overexpressed in HepG2 and Hep3B cells by $\triangle^{12}-P G J_{2}$ and induced apoptosis through activation of caspase 1 (Ahn et al., 2002). Also GRR (Gly rich region) region of Sox-4 was proved to induce apoptosis directly for itself (Eun-Hae Hur, unpublished). Based on these preliminary information, we made an attempt to examine the expression of Sox-4 in HeLa and HeLa B4 cells. Both HeLa and HeLa B4 cells expressed Sox-4 at $12 \mathrm{~h}$, keeping its levels till the apoptosis completed. It is possible to assume that apoptosis-inducing ability of Sox-4 might be attenuated by bcl-2 although expression of Sox-4 was not affected by bcl-2 protein. And this suggests that Sox-4 protein might have an influence on mitochondria signaling pathway somehow. z-VAD-fmk results which inhibit the dissipation of $\Delta \psi_{m}$ suggested that Sox-4 might be activating the casapses which exist in upstream of mitochondria.

This supposition might explain how z-VAD-fmk can block dissipation of $\triangle \psi_{\mathrm{m}}$ in $\triangle^{12}-P G J_{2}$-induced apoptosis in HeLa cells. Also complete inhibition of $\Delta \psi m$ depolarization by z-VAD-fmk suggests that early events of $\triangle^{12}-P J_{2}$-induced apoptosis might be solely dependent on caspases. It seemed that no other caspase-independent pathway, AIF, might participate in $\triangle^{12}-P G J_{2}$-induced apoptosis. But it should be proved that $\triangle^{12}-P G J_{2}$ or Sox-4 might be able to disrupt $\Delta \psi_{\mathrm{m}}$ of isolated mitochondria directly. In addition, upstream caspases which were thought to be involved in $\triangle^{12}-\mathrm{PGJ}_{2}$-induced apoptosis should be proved more closely. Supposing the existence of upstream caspases should be the acceptable answer for the blocking of $z-V A D-f m k$ to $\triangle \psi_{m}$, if it does exist, in $\triangle^{12}-P G J_{2}$-induced apoptosis.

In conclusion, our data suggested that $\triangle^{12}-\mathrm{PGJ}_{2}$ induced apoptosis utilized a caspase-dependent, AIFindependent pathway in HeLa cells. Anti-apoptotic bcl-2 protein partially attenuated cell death, including depolarization of $\Delta \psi_{\mathrm{m}}$, release of cytochrome $c$ and activation of caspases, and this processes might be regulated by $\triangle^{12}-P_{G}$-induced Sox-4 protein. 


\section{Acknowledgement}

This study was supported by a grant of Health Technology Planning and Evaluation Board Project (02-PJ1-PG10-20802-0003), Ministry of Health and Welfare, Republic of Korea. And we also thanks to Prof. Jeong-Hwa Lee for providing HeLa B4 cells and Dr. Hyangshuk Rhim for Sox-4 antibody.

\section{References}

Ahn SG, Jeong SY, Rhim HS, Kim IK. The role of c-Myc and heat shock protein 70 in human hepatocarcinoma Hep3B cells during apoptosis induced by prostaglandin $A 2$ and $\triangle^{12}$. $\mathrm{PGJ}_{2}$. Biochimica Biophysica Acta 1998;1448:115-25

Ahn SG, Cho GH, Jeong SY, Rhim HS, Choi JY, Kim IK. Identification of cDNAs for Sox-4, an HMG-Box Protein, and a novel human homolog of yeast splicing factor SSF-1 differentially regulated during apoptosis induced by prostaglandin $A_{2} / \triangle^{12}-P G J_{2}$ in Hep3B cells. Biochem Biophys Res Commun 1999;260:216-21

Ahn SG, Kim HS, Jeong SW, Kim BE, Rhim HS, Shim JY, Kim JW, Lee JH, Kim IK. Sox-4 is a positive regulator of Hep3B and HepG2 cells' apoptosis induced by prostaglandin $(P G) A_{2}$ and $\triangle^{12}-P J_{2}$. Exp Mol Med 2002;34:243-9

Atan G, James MM, Stanley JK. Bcl-2 family members and the mitochondria in apoptosis. Genes Develop 1999;13:1899 $-911$

Bains SK, Mone A, Tso JY, Lucas D, Byrd JC, Weiner GJ, Green JM. Mitochondria control of cell death induced by anti-HLA-DR antibodies. Leukemia 2003;17:1357-65.

Damien A, Philippe $P$, Jean-Claude M, Bruno A, Jerome E, Jean CA. Mitochondrial release of apoptosis-inducing factor occurs downstream of cytochrome $c$ release in response to several proapoptotic stimuli. J Cell Biol 2002;159:923-9

Damien A, Brigitte G, Mariusz K, Juanita CS, Francesco C, Richard JY. Mitochondrial release of AIF and EndoG requires caspase activation downstream of Bax/Bak-mediated permeabilization. EMBO J 2003;22:4385-99

David JG, Brighid AC, Dietrich OR, Jonathan CC, Catherine B, Guido K, Cornelis VB, Philippe M, David WH, Bruce MM. Mitochondrial release of apoptosis-inducing factor and cytochrome $\mathrm{c}$ during smooth muscle cell apoptosis. Am J Pathol 2001;159:305-11

Ella BW, Donald DN, Douglas RG. Mitochondrial cytochrome c release in apoptosis occurs upstream of DEVD-specific caspase activation and independently of mitochondrial transmembrane depolarization. EMBO J 1998;17:37-49.

Eric D, Dominique N, Luigi R, Markus Loeffler, Santos AS, Naoufal Z, Guido K. Apoptosis-inducing factor (AIF): a ubiquitous mitochondrial oxidoreductase involved in apoptosis. FEBS Lett 2000;476:118-23

Fukushima M, Kato T, Ota K, Arai Y, Narumiya S, Hayaishi O. 9-deoxy- $\Delta^{9}$-prostaglandin $D_{2}$, a prostaglandin $D 2$ derivative with potent antineoplastic and weak smooth musclecontracting activities. Biochem Biophys Res Commun 1982; 109:626-33
Fukushima M, Sasaki H, Fukushima S. Prostaglandin $J_{2}$ and related compounds. Mode of action in $\mathrm{G} 1$ arrest and preclinical results. Ann NY Acad Sci 1994;744:161-5

Gael R, Natacha B, Victor JY, Thomas M, Manuel R, Frederic D, Cecile D, Helene MB, Marika S, Santos AS. Mitochondrial dysfunction in CD47-mediated caspase-independent cell death: ROS production in the absence of cytochrome c and AIF release. Biochimie 2003;85:741-6

Hans KL, Santos AS, Josef P, Guido K. Apoptosis inducing factor (AIF): a phylogenetically old, caspase-independent effector of cell death. Cell Death Differ 1999;6:516-24

Hur EH, Hur WH, Choi JY, Kim IK, Kim HY, Yoon SK, Rhim HS. Functional identification of the pro-apoptotic effector domain in human Sox4. Biochem Biophy Res Commun 2004;325:59-67

Isabel M, Patricia PG, Pilar G, Daniel RF, Alberto A, Javier $N$. Cladribine induces apoptosis in human leukaemia cells by casapse-dependent and -independent pathways acting on mitochondria. Biochem J 2001;359:537-46

Kim BE, Roh SR, Kim JW, Jeong SW, Kim IK. cytochrome c-dependent Fas-independent apoptotic pathway in HeLa cells induced by $\Delta^{12}$-prostaglandin $\mathrm{J}_{2}$. Exp Mol Med 2003; 35:293-300

Kim GT, Chun YS, Park JW, Kim MS. Role of apoptosisinducing factor in myocardial cell death by ischemiareperfusion. Biochem Biophys Res Commun 2003;309: 619-24

Kim HS, Rhim HS, Jeong SW, Kim JW, Kim IK. Induction of apoptosis dependent on caspase activities and growth arrest in HL-60 cells by PGA2. Prostaglandins Other Lipid Med 2002;70:169-83

Kim IK, Lee JH, Sohn HW, Kim HS, Kim SH. Prostaglandin $A_{2}$ and $\Delta^{12}$-prostaglandin $J_{2}$ induce apoptosis in L1210 cells. FEBS Lett 1993;321:209-14

Koizumi T, Negishi M, Ichikawa A. Activation of heat shock transcription factors by $\triangle^{12}$-prostaglandin $J_{2}$ and its inhibition by intracellular glutathione. Biochem Pharmacol 1993;45: 2457-64

Li LY, Luo X, Wang $X$. Endonuclease $G$ is an apoptotic DNase when released from mitochondria. Nature 2001;412: 95-9

Ly JD, Grubb DR, Lawen A. The mitochondrial membrane potential $\left(\Delta \psi_{m}\right)$ in apoptosis; an update. Apoptosis 2003; 8:115-28

Maria van G, Nele F, Geert van L, Xavier S, Peter V. Mitochondrial intermembrane proteins in cell death. Biochem Biophys Res Commun 2003;304:487-97

Neeru K, HN Jayaram, Neeta S. Benzamide riboside induced mitochondrial mediated apoptosis in human lung cancer H520 cells. Life Sci 2004;75:179-90

Nele F, Marjan VG, Geert VL, Xavier S, Peter V. Bcl-2 family members as sentinels of cellular integrity and role of mitochondrial intermembrane space proteins in apoptotic cell death. Acta Haematol 2004;111:7-27

Newcomb EW, Tamasdan C, Entzminger Y, Alonso J, Friedlander D, Crisan D, Mille DC, Zagzag D. Flavopiridol 
induces mitochondrial-mediated apoptosis in murine glioma GL261 cells via release of cytocrome $c$ and apoptosis inducing factor. Cell cycle 2003;2:243-50

Odani N, Negishi M, Takahashi S, Kitano Y, Kozutsumi Y, Ichikawa A. Regulation of BiP gene expression by cyclopentenone prostaglandins through unfolded protein response element. J Biol Chem 1996;271:16609-13

Parrish J, Li L, Klotz K, Ledwich D, Wang X, Xue D. Mitochondrial endonuclease $G$ is important for apoptosis in C. elegans. Nature 2001;412:90-4

Patrice L, Ximena OA, Yuri L. Requirement for caspase-2 in stress-induced apoptosis before mitochondrial permeabilization. Science 2002;297:1352-54

Perez-Galan P, Marzo I, Giraldo P, Rubio-Felix D, Lasierra $P$, Larrad L, Anel A, Naval J. Role of caspases and apoptosis-inducing factor (AIF) in cladribine-induced apoptosis of B cell chronic lymphocytic leukemia. Leukemia 2002;16:2106-2114

Sai LS, Sridhar M, Kathleen NO, Ekambar RK, Sudhir A, Bridget SZ. Survivin inhibition induces human neural tumor cell death through caspase-independent and -dependent pathways. J Neurochem 2001;79:426-36

Santos AS, Hans KL, Naoufal Z, Isabel M, Bryan ES, Grg MB, Joan M, Etienne J, Paola C, Markus L, Nathanael L, David RG, Ruedi A, David PS, Josef MP, Guido K. Molecular characterization of mitochondrial apoptosis-inducing factor. Nature 1999:397:441-6

Sean PC, Andre F, Jason GM, Steven MC, Francesco C, Seong-Woon Y, Ted MD, Valina LD, David SP, Guido K, Ruth SS. Apoptosis-inducing factor is involved in the regulation of caspase-independent neuronal cell death. J Cell Biol 2002;158:507-17

Sean PC, Valina LD, Ruth SS. Role of AIF in caspasedependent and caspase-independent cell death. Oncogene 2004;23:2785-96

Senye T, Noriko O, Keiichiro T, Kyoji F, Masaaki S, Atsushi I, Manabu N. Localization of a cyclopentenone prostaglandin to the endoplasmic reticulum and induction of BiP mRNA.
Biochem J 1998:335:35-42

Shoichi S, Senye T, Nobumasa T, Tohru H, Toshiyuki S. 15-Deoxy- $\triangle^{12,14}$-prostaglandin $J_{2}$ induces apoptosis through activation of the CHOP gene in HeLa cells. Biochem Biophys Res Commun 2003;311:17-23

Stacy LS, Virginia MD, JOseph G, Georage LM. The kinetics of translocation of Smac/DIABLO from the mitochondria to the cytosol in HeLa cells. J Biol Chem 2002;277:45715-8

Stuart AL, Ella BW. Dueling activities of AIF in cell death versus Survival: DNA binding and redox activity. Cell 2002;111:147-50

Tomomi K, Donald DN. Bcl-2-family proteins and the role of mitochondria in apoptosis. Curr Opin Cell Biol 2003;15:691-9

Tong L, Brook B, Douglas G. Rapid induction of mitochondrial events and caspase-independent apoptosis in Survivin-targeted melanoma cells. Oncogene 2004;23:39-48.

van de Wetering $M$, Oosterwegel $M$, van Norren $K$, Clevers H. Sox-4, an Sry-like HMG box protein, is a transcriptional activator in lymphocytes. EMBO J 1993;12:3847-54

van Loo G, Schotte P, van Gurp M, Demol H, Hoorelbeke $B$, Gevaert K, Rodriguez I, Ruiz-Carrillo A, Vandekerckhove J, Declercq W, Beyaert R, Vandenabeele P. Endonuclease $G$ : a mitochondrial protein released in apoptosis and involved in caspase-independent DNA degradation. Cell Death Differ 2001;8:1136-42

Xavier S, Nele F, Lieselotte VW, Maria VG, Geert VL, Peter $V$. Toxic proteins released from mitochondria in cell death. Oncogene 2004;23:2861-74

Xu DZ, Susan KG, Peter H. Staurosporine induces apoptosis of melanoma by both caspase-dependent and -independent apoptotic pathways. Mol Can Therap 2004;3:187-97

Yin G, Srinivasa MS, Anne D, Teresa FA, Emad SA. Caspase-2 induces apoptosis by releasing proapoptotic proteins from mitochondria. J Biol Chem 2002;277:13430-7

Yoshihide T. Cell death regulation by the Bcl-2 protein family in the mitochondria. J Cell Phys 2003;195:158-67 